\title{
Enhancement of the photochromic switching speed of bithiophene azo dyes
}

\author{
Paulo J. Coelho ${ }^{a,{ }^{\star \star}}$, M. Cidália R. Castrob ${ }^{\text {, Sara S. M. Fernandes }}{ }^{\text {b }}$, A. Maurício C. \\ Fonsecab $^{\mathrm{b}}$, M. Manuela M. Raposo ${ }^{\mathrm{b}}$
}

${ }^{a}$ Centro de Química-Vila Real, Universidade de Trás-os-Montes e Alto Douro, 5001-801 Vila Real, Portugal.

b Centro de Química, Universidade do Minho, Campus de Gualtar, 4710-057 Braga, Portugal.

\section{Abstract}

A series of heteroaryl substituted bithiophene azo dyes in solution were irradiated with visible light to promote the azo $E-Z$ isomerization and then the kinetics of the thermal $Z-E$ back reaction was studied. The speed of this process is strongly influenced by the nature of the aromatic ring linked to the $\mathrm{N}=\mathrm{N}$ function. While thiazole bithiophene azo dyes exhibit high switching speeds between the two isomers, but limited interconversion, for benzothiazole and substituted thiadiazole bithiophene azo dyes the switching between the two photoisomers can be performed in 3 seconds with a significant conversion of the trans-isomer to the thermal unstable cis-isomer (19-21\%) and therefore a notable variation of the visible spectrum is observed.

\footnotetext{
* Corresponding author Tel.: +351 259 350284; Fax: +351 259 350480; e-mail address: pcoelho@utad.pt
} 


\section{Graphical abstract}

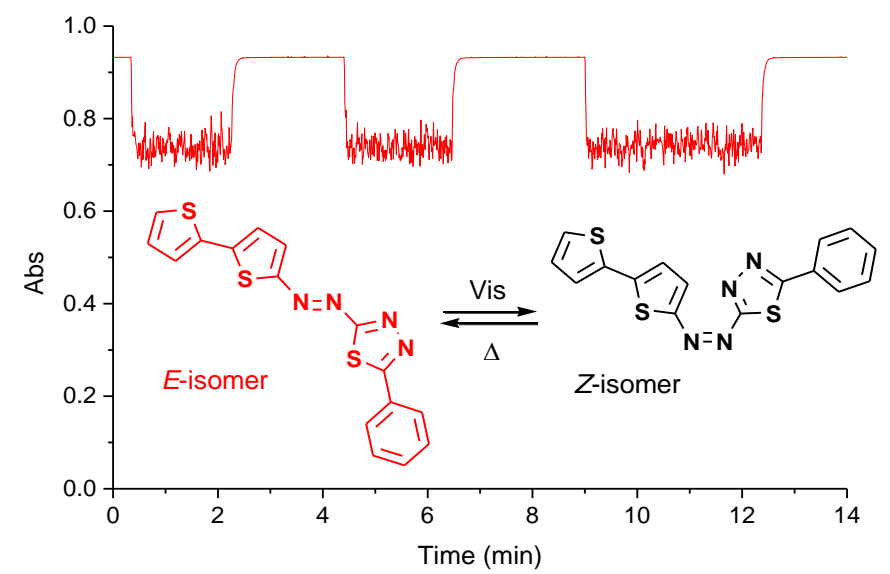

Keywords: Photochromism, heterocyclic azo dyes, bithiophene, molecular switches. 
Azobenzene exist in two isomeric forms, the $E$ (trans) and $Z$ (cis), which exhibit different absorption spectra. ${ }^{1}$ The more stable E-form can be partially converted to the Zform by applying light, and with time, an equilibrium state is established between the populations of trans and cis isomers with a noticeable change in UV-Vis absorption spectra. The $Z$-form is unstable and usually returns thermally to the $E$ isomer, following a mono-exponential kinetics, although light of a different wavelength can be used to promote this reaction (Scheme 1).

\section{Scheme 1}

The incorporation of these molecular photoswitches in different matrixes, dispersed or covalently linked, led to the preparation of several photoresponsive organic or hybrid advanced materials with a variety of photochromic, ${ }^{2-6}$ luminescent, ${ }^{7-9}$ non-linear optics, ${ }^{10-13}$ polarized light-induced anisotropy, ${ }^{14-16}$ and mechanical properties. ${ }^{17-24}$ The performance of these materials rely on our ability to control the kinetics of the $E-Z$ photoisomerization which can be achieved by the proper choice of the environmental media ${ }^{3,6}$ or by the change in the azobenzene structure..$^{25-28}$

Although a large variety of diarylazo compounds are used in the design of optical materials, only a few reports concerning the photoisomerization of heterocyclic azo dyes can be found in the literature. ${ }^{29-30}$ In the last years we have synthesized a large variety of heterocyclic azo dyes substituted by electron-donating and electron-withdrawing groups ('push/pull' substitution pattern) that possess solvatochromic, photochromic and nonlinear optical (NLO) properties which are influenced by the electronic nature of the $\pi$-conjugated bridge (thienylpyrrole or bithiophene) and by the substitution pattern on the aryl and heteroaryl-diazene moieties (Figure 1). ${ }^{31-38}$

Figure 1 
Earlier, we observed that bithiophene azo dyes exhibit photochromic properties at room temperature, although the speed of the photo and thermal isomerization is quite slow: visible light irradiation of phenyl substituted 2,2'-bithiophene azo dyes, in solution, leads in less than $30 \mathrm{~s}$ to a significant decrease of the absorbance at $\lambda_{\max }(35-50 \%)$ due to the conversion of the $E$-isomer to the $Z$-isomer. When the irradiation ceases the system returns to the initial state following a mono-exponential kinetics with an half-life time between 18 to $69 \mathrm{~s}$, depending on the aryl substituents. As a result a noticeable colour intensity change is easily perceivable by a naked eye, due to the switching between the two isomers ${ }^{38}$ In order to increase the speed of this process we decided to substitute the phenyl ring by thiazole, benzothiazole or thiadiazole heterocycles which are known to have a marked influence on the thermal stability of the $Z$-isomer. ${ }^{33,35}$

The thiazolyl-, benzothiazolyl- and dithiazolyl- 2,2'-bithiophene azo dyes presented in this study can be divided in four groups according to the nature of the aromatic ring linked to the azo group and the position of that linkage (Figure 2) ${ }^{39-40}$ Azo bithiophene dyes 1, 3 and 4 possess the azo group linked to the 5 position of the bithiophene while in azo dyes 2 the linkage is at the 4 position; azo bithiophene dyes 1 and 2 are linked to thiazole group whereas azo dyes $\mathbf{3}$ and $\mathbf{4}$ are linked to benzothiazole or substituted thiadiazole nuclei, respectively.

Figure 2

The photochromic behaviour of these molecules was studied in $2.0 \times 10^{-5} \mathrm{M}$ acetone solutions by measuring the absorbance of the solution at the maximum wavelength of absorption while irradiating with visible light. The samples solutions $(3.5 \mathrm{~mL})$ were placed in a thermostated $\left(20^{\circ} \mathrm{C}\right) 10 \mathrm{~mm}$ quartz cell $(3.5 \mathrm{~mL})$ equipped with magnetic stirring. The visible spectrum was measured using a Cary 50 Varian spectrometer while irradiating with visible light $(>420 \mathrm{~nm})$ from a $150 \mathrm{~W}$ ozone free xenon lamp (6255 Oriel Instruments, 
range $250-2400 \mathrm{~nm}$ range). The light from the UV-vis lamp was filtered using a water filter and a long-pass filter (Schott GG 420) and carried to the spectrophotometer holder, perpendicularly to the monitoring beam, using a fibre-optic system.

In acetone all compounds afforded deeply coloured solutions (orange to red) with molar absorptivities ranging from $1.1 \times 10^{4}$ to $3.3 \times 10^{4} \mathrm{M}^{-1} \mathrm{~cm}^{-1}$. The maximum absorption band of the stable trans form of unsubstituted thiazole and thiadiazole azo dyes 1a and $\mathbf{4 a}$ was found at 480 and $477 \mathrm{~nm}$, respectively. A strong bathochromic shift of the maximum wavelength of absorption (33-43 nm) was observed when strong donating substituents $\left(\mathrm{OR}\right.$ or $\mathrm{NR}_{2}$ ) were placed in the $5^{\prime}$ or 4 position of the bithiophene ring (compounds $\mathbf{1 b}-\mathbf{c}, \mathbf{e}-$ f, 2a-b). A lower bathochromic shift $(7-25 \mathrm{~nm})$ was measured when methyl, bromine, phenyl or p-fluorophenyl were placed at the thiazole or dithiazole rings (compounds $\mathbf{1 d}$, $4 b-d)$.

Visible light irradiation of acetone solutions of all azo dyes 1-4 (except 2a) led to a decrease of the absorption at $\lambda_{\max }(2-45 \%)$ and, at the same time, an increase in the band located near $400 \mathrm{~nm}$, due to the $E-Z$ photoisomerization (Figure 3 ). When the light source was removed the absorption increased in few seconds to the initial value. The thermal coloration curves were analysed evaluating the fitting of the experimental data to the mono-exponential equation:

$$
A(t)=A_{1} e^{-k t}+A_{\max }
$$

where $A(t)$ is the absorbance at $\lambda_{\max }$ at any instant $t, A_{1}$ a proportional factor, $k$ the thermal colouration rate and $A_{\max }$ the absorbance in the dark when time approaches infinity. The mono-exponential model was found to accurately fit our data which indicates that the isomerization proceeds via a single pathway. The procedure was repeated several times and the behaviour was fully reproducible indicating that under these experimental conditions no degradation was observed. 
Figure 3

For thiazole azo dye 1a the absorption decrease under visible light was very fast, but short (8\%) suggesting a limited transformation of the more stable $E$-isomer into the thermal unstable Z-isomer (Figure 4). The fitting of the colouration/time curve indicates a life-time $\left(t_{1 / 2}\right)$ of $0.66 \mathrm{~s}$ for the Z-isomer, which means that in $3 \mathrm{~s}$ the system returns to the initial state.

Figure 4

A similar behaviour was observed when methoxy and ethoxy groups were introduced on the bithiophene system (compounds $\mathbf{1 b}$ and 1c) which indicates that these substituents have no effect on the $E-Z$ isomerization kinetics. On the other hand the introduction of a methyl group on the thiazole group (compounds $\mathbf{1 d}$ and 1e) led to a slight increase of the kinetics of the thermal $Z-E$ isomerization and as a result, for these compounds the irradiation with visible light led to a very low absorption decrease (2\%). Under continuous visible irradiation conditions, the decrease in the absorbance at $\lambda_{\max }$ for the $E$-isomer is inversely related to the kinetic rate of the colouration process, so lower absorbance variations are usually observed with the fastest systems. ${ }^{41}$ The formyl-thiazole azo dye $\mathbf{1 g}$ exhibited very high switching speed and therefore under visible irradiation a very limited absorbance variation was also detected. This behaviour is in accordance with recent theoretical results that indicate that strong electron withdrawing substituents on the benzene ring of azobenzene lowers the ground-state inversion barrier height, making it easier to isomerize. ${ }^{42}$

As observed before, the change on the azo linkage position from the 5 to the 4 position of the bithiophene moiety decreased the photochromic properties and for 
compounds $\mathbf{2} \mathbf{a}, \mathbf{b}$ a near constancy of the absorbance was observed with or without visible light irradiation. ${ }^{38}$

The annelation of a benzene ring to the thiazole group (compound 3 ) had a strong effect on the absorption variation while keeping the thermal $Z-E$ isomerization kinetics at the same level. This compound shows a very fast and pronounced response to the light stimulus (Figure 5): visible irradiation leads in 3 seconds to $19 \%$ decrease of the absorption and, after removal of the light source, the system returns to the initial state in another 3 seconds.

Figure 5

The substitution of the thiazole ring by a thiadiazole (compound 4 a) led to a very significant decrease (50 times) of the thermal $Z-E$ kinetic constant rate with the concomitant increase of the life-time of the Z-isomer (33 s) and therefore to a much higher absorption variation: the thiadiazole azo dye 4 a loses $45 \%$ of its colouration under visible irradiation but the return to the initial form is much slower (Figure 6). The kinetics of the azo isomerization reaction is very sensible to the presence of substituents on the thiadiazole ring. The introduction of bromine, phenyl or p-fluorophenyl groups led to an important increase of the kinetics of the thermal $Z-E$ isomerization (7.5-26 times) and as a result compound $\mathbf{4 c}$ has a similar behaviour as the non substituted benzothiazole azo dye 3. For these two dyes the switching between the two photoisomers can be performed in less than 5 seconds with a notable absorption variation in the visible region.

Figure 6 
Compared to previously described bithiophene aryldiazenes (see compound $\mathbf{5}$ in table 1$)^{38}$ this set of thiazole, benzothiazole or thiadiazole bithiophene azo dyes shows much faster switching speeds between the two photoisomers (up to 180 times) and for benzothiazole azo dye $\mathbf{3}$ and thiadiazole azo dyes $\mathbf{4 b - d}$ the visible light irradiation leads to a noteworthy change in the visible spectrum which is indicative of a significant conversion (18 to $32 \%$ ) of the trans-isomer into the cis-isomer.

In summary, the kinetics of the $E-Z$ transformation of bithiophene azo dyes is strongly influenced by the nature of the heterocyclic diazene moiety. Thiazole bithienyl azo dyes exhibit very fast photoisomerization but only a small percentage of the $E$-isomer is converted to the $Z$-isomer and therefore the amplitude of the absorption variation is small $(2-8 \%)$. The annelation of a benzene ring into the thiazole led to a much higher colour variation perception (19\%) while maintaining the kinetics of the thermal isomerization at the same level. Thiadiazole bithienyl azo dyes are very sensible to the presence of substituents on the thiadiazole ring and for these compounds the kinetic of the photoisomerization can be easily controlled: while for unsubstituted thiadiazole bithiophene azo dye 4a the $Z-E$ transformation is very slow, the introduction of a phenyl group in the 4 position of the thiadiazole led to a new dye (4c) for which the switching between the two photoisomers can be performed in 5 seconds with a notable variation of the visible spectrum. 


\section{Acknowledgments}

Thanks are due to the Fundação para a Ciência e Tecnologia (Portugal) and FEDERCOMPETE for financial support through the Centro de Química - Universidade do Minho, Projects PTDC/QUI/66251/2006 (FCOMP-01-0124-FEDER-007429), PEstC/QUI/UI0686/2011 (F-COMP-01-0124-FEDER-022716) and a PhD grant to M. C. R. Castro (SFRH/BD/78037/2011). The NMR spectrometer Bruker Avance III 400 is part of the National NMR Network and was purchased within the framework of the National Program for Scientific Re-equipment, contract REDE/1517/RMN/2005 with funds from POCI 2010 (FEDER) and FCT.

\section{References and notes}

1. Rau, H. In Photochemistry and photophysics; Rabek, J. F., Ed.; CRC Press Inc: Florida, 1990, Vol. II, pp 119-141.

2. Gimenez, R.; Millaruelo, M.; Pinol, M.; Serrano, J.L.; Vinuales, A.; Rosenhauer, R.; Fischer, T.; Stumpe, J. Polymer 2005, 46, 9230-9242.

3. Evans, R.A.; Hanley, T.L.; Skidmore, M.A.; Davis, T.P.; Such, G.K.; Yee, L.H.; Ball, G.E.; Lewis, D.A. Nat. Mater. 2005, 4, 249-253.

4. Takahashi, M.; Okuhara, T.; Okohari, Y.T.; Kobayashi, K. J.Colloid Interf. Sci. 2006, 296, 212-219.

5 Ueda, M.; Kim, H.B.; Ikeda, T.; Ichimura, K. Chem. Mater. 1992, 4, 1229-1233. 
6. Garcia-Amoros, J.; Finkelmann, H.; Velasco, D. Phys. Chem. Chem. Phys. 2011, 13, 11233-11238.

7. Yutaka, T.; Mori, I.; Kurihara, M.; Mizutani, J.; Tamai, N.; Kawai, T.; Irie, M.; Nishihara, H. Inorg. Chem. 2002, 41, 7143-7150.

8. Ghedini, M.; Pucci, D.; Calogero, G.; Barigelletti, F. Chem. Phys. Lett. 1997, 267, 341344

9. Niimi, T.; Umeda, M. J. Appl. Phys. 1993, 74, 465-468.

10. Quu, L.; Shen, Y.Q.; Hao, J.M.; Zhai, J.F.; Hu, Z.F.; Zhang, T.; Zhao, Y.X.; Clays, K.; Persoons, A. J. Mater. Sci. 2004, 39, 2335-2340.

11. Borbone, F.; Carella, A.; Ricciotti, L.; Tuzi, A.; Roviello, A.; Barsella, A. Dyes Pigments 2011, 88, 290-295.

12. Bosc, D.; Foll, F.; Boutevin, B.; Rousseau, A. J. Appl. Polym. Sci. 1999, 74, 974-982.

13. Chen, X.B.; Zhang, J.J.; Zhang, H.B.; Jiang, Z.H.; Shi, G.; Li, Y.B.; Song, Y.L. Dyes Pigments 2008, 77, 223-228.

14. Atassi, Y.; Chauvin, J.; Delaire, J.A.; Delouis, J.F.; Fanton-Maltey, I.; Nakatani, K. Pure Appl. Chem. 1998, 70, 2157-2166. 
15. Pan, X.; Xiao, S.F.; Wang, C.S.; Cai, P.; Lu, X.M.; Lu, Q. H. Opt. Commun. 2009, 282, 763-768.

16. Forcen, P.; Oriol, L.; Sanchez, C.; Alcala, R.; Hvilsted, S.; Jankova, K.; Loos, J. J. Polym. Sci. Pol. Chem. 2007, 45, 1899-1910.

17. Natansohn, A.; Rochon, P. Can. J. Chem. 2001, 79, 1093-1100.

18. Yager, K.G.; Barrett, C.J. Macromolecules 2006, 39, 9320-9326.

19. Juan, M.L.; Plain, J.; Bachelot, R.; Royer, P.; Gray, S.K. Wiederrecht, G.P. ACS Nano 2009, 3, 1573-1579.

20. Petrossian, A.; Residori, S. Opt. Commun. 2003, 228, 145-153.

21. Ferri, V.; Elbing, M.; Pace, G.; Dickey, M.D.; Zharnikov, M.; Samori, P.; Mayor, M.; Rampi, M.A. Angew. Chem. Int. Edit. 2008, 47, 3407-3409.

22. Mativetsky, J.M.; Pace, G.; Elbing, M.; Rampi, M.A.; Mayor, M.; Samori, P. J. Am. Chem. Soc. 2008, 130, 9192-9193.

23. Silvi, S.; Venturi, M.; Credi, A. J. Mater. Chem. 2009, 19, $2279-2294$.

24. Russew, M.M.; Hecht, S. Adv. Mater. 2010, 22, 3348-3360. 
25. Ke, X.J.; Yan, X.Z.; Song, S.Y.; Li, D.Q.; Yang, J.J.; Wang, M.R. Opt. Mater. 2007, 29, $1375-1380$.

26. Muri, M.; Schuermann, K.C.; de Cola, L.; Mayor, M. Eur. J. Org. Chem. 2009, 25622575 .

27. Kumar, S.K.; Hong, J.D.; Lim, C.K.; Park, S.Y. Macromolecules 2006, 39, 3217-3223.

28. Liao, L.X.; Stellacci, F.; McGrath, D.V. J. Am. Chem. Soc. 2004, 126, 2181-2185.

29. Kucharski, S.; Janik, R.; Motschmann, H.; Raduge, C. New J. Chem. 1999, 23, 765771.

30. Wang, G.; Gan, F.; Wang, J.; Yang, L.; Xu, Z. J. Phys. Chem. Solids 2002, 63, 501506.

31. Raposo, M.M.M.; Sousa, A.M.R.C.; Fonseca, A.M.C.; Kirsch, G. Tetrahedron 2005, 61, 8249-8256.

32. Coelho, P.J.; Carvalho, L.M.; Fonseca, A.M.C.; Raposo, M.M.M. Tetrahedron Lett. 2006, 47, 3711-3714.

33. Raposo, M.M.M.; Fonseca, A.M.C.; Castro, M.C.R.; Belsley, M.; Cardoso, M.F.S.; Carvalho, L.M.; Coelho, P.J. Dyes Pigments 2011, 91, $62-73$. 
34. Raposo, M.M.M.; Castro, M.C.R.; Schellenberg, P.; Fonseca, A.M.C.; Belsley, M. Tetrahedron 2011, 67, 5189-5198.

35. Coelho, P.J.; Castro, M.C.R.; Fonseca, A.M.C.; Raposo, M.M.M. Dyes Pigments 2012, 92, 745-748.

36. Raposo, M.M.M.; Ferreira, A.M.F.P.; Belsley, M.; Moura, J.C.V.P. Tetrahedron 2008, $64,5878-5884$.

37. Raposo, M.M.M.; Ferreira, A.M.F.P.; Amaro, M.; Belsley, M.; Moura, J.C.V.P. Dyes Pigments 2009, 83, 59-65.

38. Coelho, P.J.; Carvalho, L.M.; Moura, J.C.V.P.; Raposo, M.M.M. Dyes Pigments 2009, $82,130-133$.

39. Raposo, M.M.M.; Castro, M.C.R.; Belsley, M.; Fonseca, A.M.C. Dyes Pigments 2011, $91,454-465$.

40. Castro, M.C.R.; Schellenberg, P.; Belsley, M.; Fonseca, A.M.C.; Fernandes, S.S.M.; Raposo, M.M.M. Dyes Pigments 2012, doi: 10.1016/j.dyepig.2012.05.014.

41. Deniel, M. H.; Lavabre D.; Micheau J. C., Photokinetics Under Continuous Irradiation, in Organic Photochromic and Thermochromic Compounds. Crano J.C.; Guglielmetti R., Eds.; Plenum Press: New York, 1998; vol. 2, chapter 3, pp. 159-201.

42. Crecca C. R.; Roitberg A. E. J. Phys. Chem. A 2006, 110, 8188-8203. 


\section{Legends}

Scheme 1. Azobenzene photoisomerization.

Figure 1. Structure of bithiophene and thienylpyrrole azo dyes bearing aryl-, thiazolyl- and benzothiazolyl-diazene moieties.

Figure 2. Structure of the bithiophene azo dyes functionalized with thiazole, benzothiazole and thiadiazole heterocycles.

Figure 3. Absorption spectra of dye $\mathbf{4 a}$ measured during visible light irradiation (1.0 min).

Figure 4. Visible irradiation/dark cycles for dye 1a.

Figure 5. Visible irradiation/dark cycle for dye 3.

Figure 6. Visible irradiation/dark cycles for dye $\mathbf{4 a}$ and $\mathbf{4 c .}$ 
Table 1. Spectrokinetic properties under continuous visible irradiation: maximum wavelength of absorption $\left(\lambda_{\max }\right)$, maximum absorbance $\left(A_{\max }\right)$, absorbance variation ( $\triangle \mathrm{Abs})$, thermal bleaching rate $\left(\mathrm{k}_{\Delta}\right)$ and half-time life $\left(\mathrm{t}_{1 / 2}\right)$ of azo dyes 1-4 and the reference bithiophene azo dye $5{ }^{36}$

\begin{tabular}{|c|c|c|c|c|c|}
\hline Azo & $\lambda_{\max }(\mathrm{nm})$ & $A_{\max }$ & $\Delta \mathrm{Abs}$ & $\mathrm{k}_{\Delta}\left(\mathrm{s}^{-1}\right)$ & $\mathrm{t}_{1 / 2}(\mathrm{~s})$ \\
\hline $1 a$ & 480 & 0.71 & $0.06(8 \%)$ & 1.05 & 0.66 \\
\hline $1 b$ & 520 & 0.68 & $0.04(6 \%)$ & 0.98 & 0.71 \\
\hline $1 c$ & 523 & 0.76 & $0.05(7 \%)$ & 1.24 & 0.56 \\
\hline $1 d$ & 487 & 0.732 & $0.016(2 \%)$ & 1.57 & 0.44 \\
\hline $1 e$ & 520 & 0.642 & $0.010(2 \%)$ & 1.50 & 0.46 \\
\hline $1 f$ & 526 & 0.729 & $0.013(2 \%)$ & 1.2 & 0.57 \\
\hline $1 \mathrm{~g}$ & 516 & 0.763 & $0.016(2 \%)$ & 3.8 & 0.18 \\
\hline $2 a$ & 514 & 0.37 & - & - & - \\
\hline $2 b$ & 520 & 0.43 & $0.01(2 \%)$ & 0.01 & 70 \\
\hline 3 & 499 & 0.575 & $0.112(19 \%)$ & 1.1 & 0.63 \\
\hline $4 a$ & 477 & 0.594 & $0.267(45 \%)$ & 0.0204 & 33 \\
\hline $4 b$ & 497 & 0.755 & $0.242(32 \%)$ & 0.153 & 4.3 \\
\hline $4 c$ & 502 & 0.932 & $0.187(21 \%)$ & 0.513 & 1.4 \\
\hline $4 d$ & 500 & 1.06 & $0.196(18 \%)$ & 0.542 & 1.3 \\
\hline 5 & 495 & 0.52 & $0.23(44 \%)$ & 0.021 & 33 \\
\hline
\end{tabular}




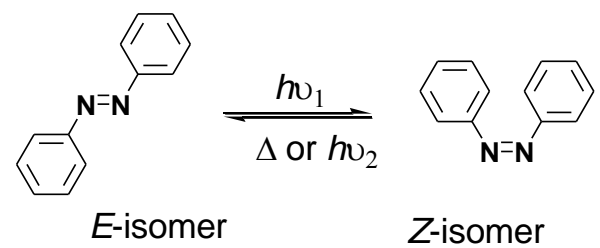

Scheme 1

Thienylpyrrole azo dyes
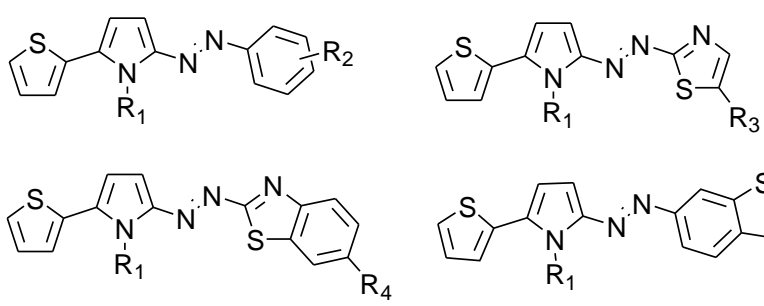

$$
\begin{array}{ll}
\mathrm{R}_{1}=\text { alkyl, aryl } & \mathrm{R}_{3}=\mathrm{H}, \mathrm{Me}, \mathrm{CHO} \\
\mathrm{R}_{2}=\mathrm{CO}_{2} \mathrm{Me}, \mathrm{CN}, \mathrm{NO}_{2} & \mathrm{R}_{4}=\mathrm{H}, \mathrm{Me}
\end{array}
$$

\section{Bithiophene azo dyes}
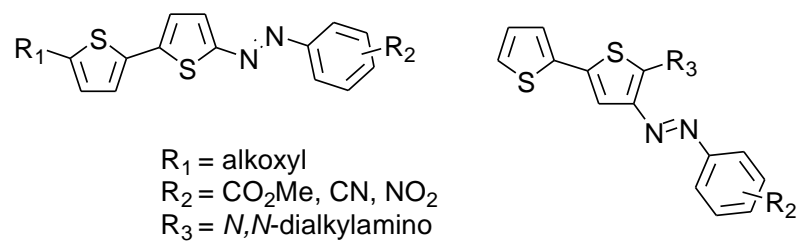

Figure 1 




1a $\mathrm{R}_{1}=\mathrm{H} \quad$ 1d $\mathrm{R}_{1}=\mathrm{H}, \mathrm{R}_{2}=\mathrm{CH}_{3}$

1b $\mathrm{R}_{1}=\mathrm{OMe}$ 1e $\mathrm{R}_{1}=\mathrm{OMe}, \mathrm{R}_{2}=\mathrm{CH}_{3}$

1c $\mathrm{R}_{1}=\mathrm{OEt}$ 1f $\mathrm{R}_{1}=\mathrm{OEt}, \mathrm{R}_{2}=\mathrm{CH}_{3}$

1 g $\mathrm{R}_{1}=\mathrm{H}, \mathrm{R}_{2}=\mathrm{CHO}$

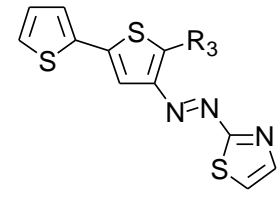

2a $\mathrm{R}_{3}=\mathrm{NEt}_{2}$

2b $R_{3}=N$


4a $\mathrm{R}_{4}=\mathrm{H} \quad 4 \mathrm{c} \quad \mathrm{R}_{4}=\mathrm{Ph}$

4b $\mathrm{R}_{4}=\mathrm{Br}$ 4d $\mathrm{R}_{4}=p-\mathrm{F}-\mathrm{Ph}$

Figure 2.

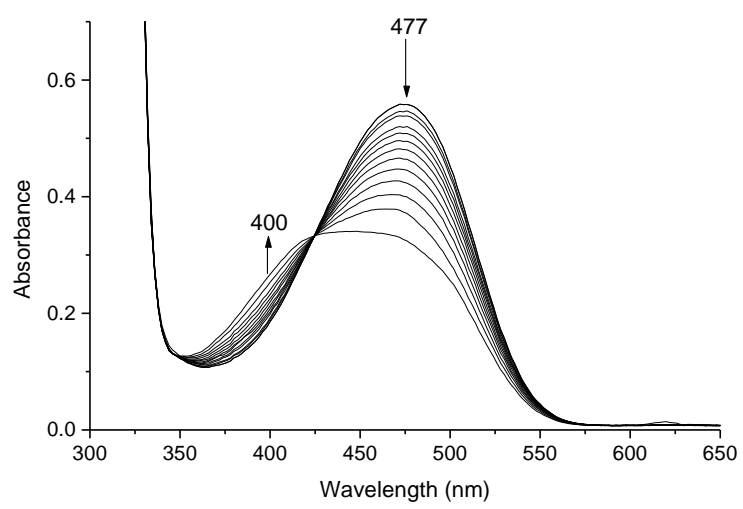

Figure 3. 


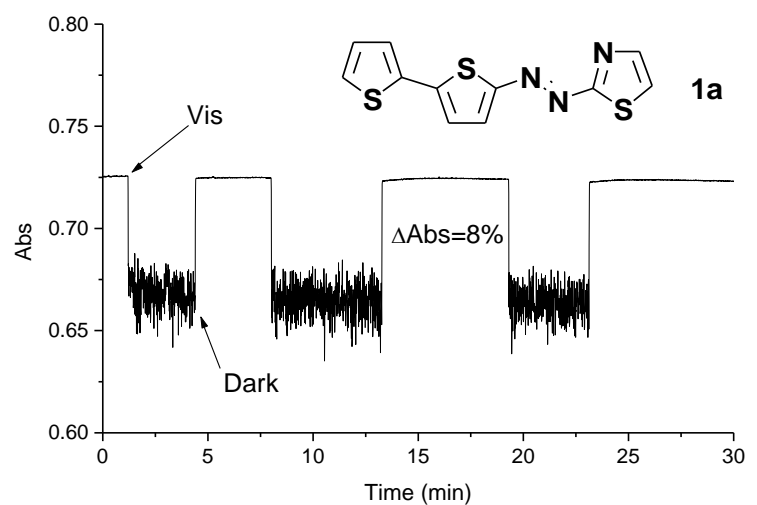

Figure 4.

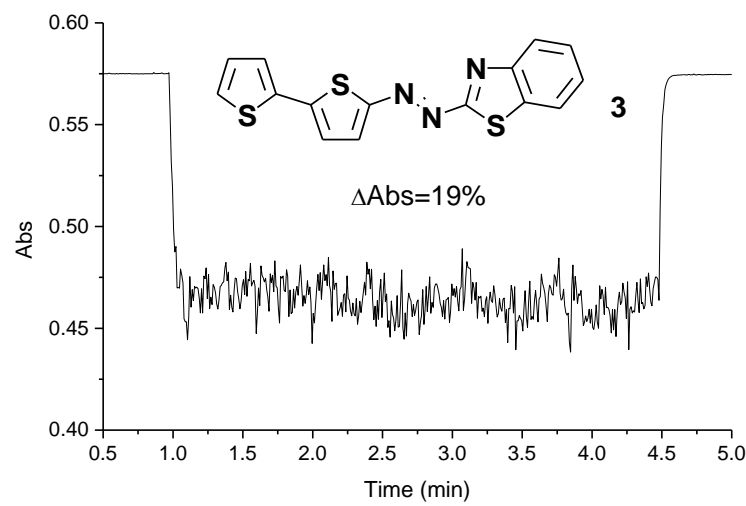

Figure 5.
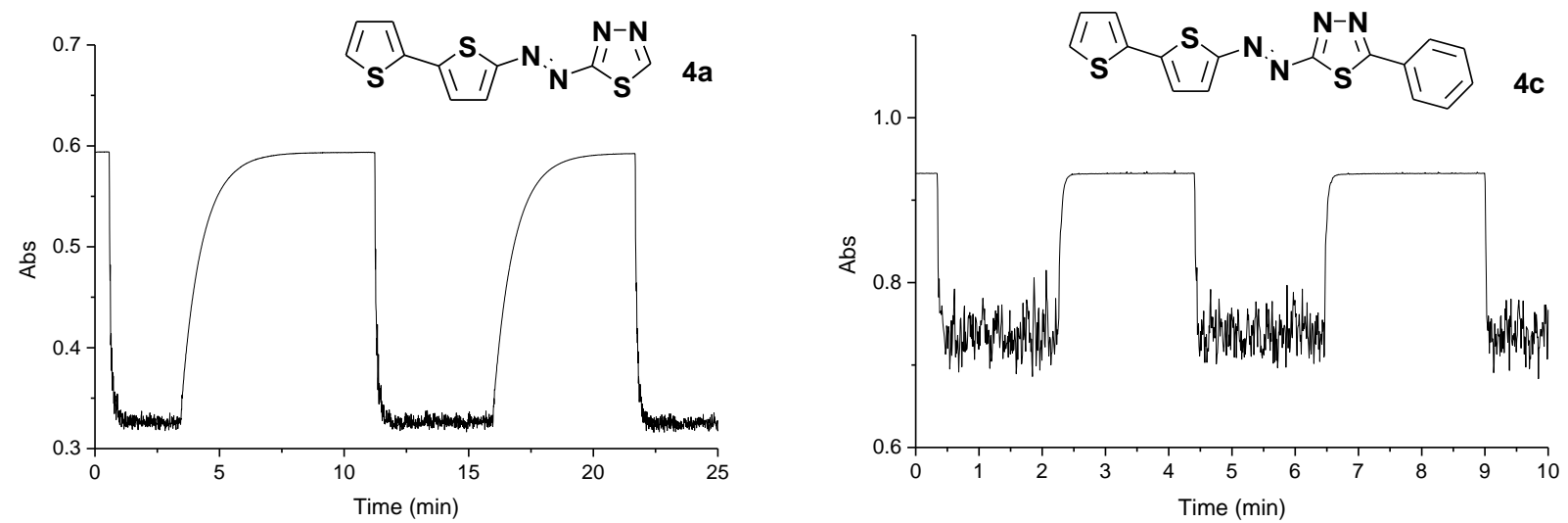

Figure 6 